\title{
Statistical Modeling of Candidate Gene Effects on Milk Production Traits in Dairy Cattle
}

\author{
J. Szyda*1 and J. Komisarek† \\ *Department of Animal Genetics, Wrocław University of Environmental and Life Sciences, 51-631, Poland \\ †Department of Cattle Breeding and Milk Production, August Cieszkowski Agricultural University of Poznań, 60-625, Poland
}

\begin{abstract}
A major objective of dairy cattle genomic research is to identify genes underlying the variability of milk production traits that could be useful in breeding programs. The candidate gene approach provides tools for searching for causative polymorphisms affecting quantitative traits. Genes with a possible effect on milk traits in cattle can be involved in different physiological pathways, such as triglyceride synthesis [acyl-CoA:diacylglycerol acyltransferase 1 gene (DGAT1)], fat secretion from the mammary epithelial tissue (butyrophilin), or entire-body energy homeostasis regulation (leptin and leptin receptor). In this study, based on data from 252 Black and White bulls from the active Polish dairy population, effects and potential interactions of 9 single nucleotide polymorphisms in the butyrophilin, DGAT1, leptin, and leptin receptor genes were investigated. Additionally, the effect of the number of additive, dominance, and epistatic genetic effects fitted into the model on the estimates of model parameters and model selection was illustrated. Phenotypic records were daughter yield deviations for milk, fat, and protein yields, obtained from a routine national genetic evaluation. Out of all the analyzed polymorphisms, DGAT1 K232A had a much larger effect on milk traits than the other single nucleotide polymorphisms considered. Estimates of the additive genetic effect of K232A expressed as half of the difference between Lys- and Ala-encoding variants were $-107.4 \mathrm{~kg}$ of milk, $5.4 \mathrm{~kg}$ of fat, and $-1.6 \mathrm{~kg}$ of protein at first parity, as well as $-120 \mathrm{~kg}$ of milk and 6.8 $\mathrm{kg}$ of fat at second parity. In terms of model selection, it was demonstrated that the modified version of Bayesian information criterion selects models with the parameterization reflecting the genetic background of the analyzed trait, while the Bayesian information criterion chooses models that are too highly parameterized. Key words: single nucleotide polymorphism, candidate gene, model selection, dairy cattle
\end{abstract}

Received November 2, 2006.

Accepted January 31, 2007.

${ }^{1}$ Corresponding author: szyda@ar.wroc.pl

\section{INTRODUCTION}

Most economically important traits in farm animals are quantitative in nature. Continuously distributed phenotypes result from the combined action of many genes with small marginal additive effects each, called polygenes, and of a certain, precisely unknown number of genes with relatively large effects, called QTL, as well as of environmental factors. A major objective of dairy cattle genomics is to identify genes underlying genetic variability of milk production traits that could be implemented in breeding programs. The candidate gene approach is one of 2 main strategies for studying the genetic background of complex traits. It is based on association tests using loci selected as ones with biological actions involved in physiology of the trait of interest (functional candidates) or in chromosome regions containing previously identified QTL (positional candidates). Many candidate genes with different functions in metabolism have been proposed as affecting milk yield and composition in dairy cattle, such as butyrophilin (BTN1A1), leptin (LEP), leptin receptor (LEPR), and acyl-CoA:diacylglycerol acyltransferase 1 (DGAT1).

The DGAT1 gene encodes a microsomal enzyme catalyzing the final step of triacylglycerol synthesis, and it has become a functional candidate gene for milk-related traits after evidence was found that lactation was defective in DGAT1-deficient mice, most probably because of impaired triglyceride production in the mammary gland (Smith et al., 2000). In cattle, DGAT1 is in the centromeric region of chromosome 14, where the presence of a QTL with a major effect on fat content and other milk characteristics has been supported by many studies (Coppieters et al., 1998; Riquet et al., 1999). The nonconservative ApA to GpC dinucleotide substitution in exon 8 changing Lys to Ala at position 232 (K232A), as well as a variable number of tandem repeat polymorphisms in the DGAT1 promoter have been identified as mutations responsible for most of chromosome 14 QTL variation (Grisart et al., 2002; Winter et al., 2002; Sanders et al., 2006).

Butyrophilin is a transmembrane glycoprotein specifically expressed on the apical surface of the mam- 
mary epithelial cells in the final stage of pregnancy and during lactation. It is also the primary protein in the membrane surrounding fat droplets in milk (Mather, 2000). Although the function of BTN1A1 is not fully understood, its expression profile suggests an important role in lactation. Studies conducted recently on BTN1A1-deficient mice have shown that functional BTN1A1 is necessary for the proper secretion of milk lipids (Ogg et al., 2004).

Leptin is a protein hormone secreted mainly from white adipose tissue (Houseknecht et al., 1998). The well-known function of leptin includes the regulation of food intake and energy expenditure. However, the hormone also appears to be implicated in many more physiological functions, including the modulation of reproduction, hormone secretion by several endocrine glands, immune and stress responses, as well as cell differentiation and proliferation (Houseknecht et al., 1998; Fruhbeck, 2001). Many leptin effects are mediated centrally, at the level of the hypothalamus. Several peripheral effects have also been described (Houseknecht et al., 1998). A widespread expression of the leptin receptor observed in cattle suggests that the hormone may act directly in most bovine tissues (Silva et al., 2002). In the mammary gland, LEPR expression changes considerably, being low in prepubertal heifers and strongly increasing at stages of massive udder development (Feuermann et al., 2004). During lactation, leptin has been shown to interact with lactogenic hormones such as prolactin to stimulate milk fat and protein synthesis (Feuermann et al., 2004).

Many polymorphisms have been found in bovine BTN1A1, LEP, LEPR, and DGAT1 genes. Some of them have not been included in any association study. For others, some relationships with milk production traits have been reported (Grisart et al., 2002; Winter et al., 2002; Buchanan et al., 2003; Komisarek et al., 2005). However, because of a relatively low number of investigations as well as a large diversity in the reported polymorphism effects between studies, most of the associations need to be confirmed before definite conclusions may be drawn. Gene causality has been proved by both genetic and functional analyses only for the K232A mutation in the DGAT1 gene (Grisart et al., 2004). Nevertheless, differences in K232A allele substitution effects between cattle populations have been reported, which may have resulted from the interaction of DGAT1 with the background genes.

The first goal of this study was to estimate additive effects of 9 single nucleotide polymorphisms (SNP) in the BTN1A1, DGAT1, LEP, and LEPR genes on milk production traits. However, in addition to additive effects, dominance and interaction effects were also considered in modeling. Although the genetic nature of analyzed traits is purely additive, such modeling allows for the analysis of the effect of other genetic parameters included in the model on the estimation of additive effects. The phenomenon of a biased estimation of additive effects in the absence of important interaction effects has already been addressed by Zeng et al. (2005) in the analysis of simulated data and was confirmed theoretically by P. Biecek and W. Klonecki (Institute of Mathematics and Informatics, Wrocław Technical University, Poland; personal communication). Regarding model selection, Bogdan et al. (2004) and Baierl et al. (2006) concluded that a commonly used Bayesian information criterion (BIC) is inappropriate for models highly parameterized with effects of many loci and proposed a modified criterion. Consequently, the second goal of our study was to investigate the problem of confounding among effects and model selection using a real data set.

\section{MATERIALS AND METHODS}

The data comprises 252 Black and White bulls from the active Polish dairy population, born from 1990 to 1998. The number of daughters per bull was high, with the average varying from 64 to 4,953 . For each bull, the following functional SNP were assessed: F16Y (Husaini et al., 1999), P35Q (Seyfert and Lüthen, 1998), and K468R (Taylor et al., 1996) in the BTN1A1 gene on bovine chromosome 23; K232A (Grisart et al., 2002; Winter et al., 2002) in the DGAT1 gene on chromosome 14; T945M (Liefers et al., 2004) in the LEPR gene on BTA3; and Y7F (Lagonigro et al., 2003), R25C (Konfortov et al., 1999), A80V (Konfortov et al., 1999), as well as promoter $\mathrm{C} / \mathrm{T}$ substitution at position -963 (Liefers et al., 2005) in the LEP gene on chromosome 4. For F16Y and Y7F, only 2 genotypes (common homozygous and heterozygous) were observed, whereas for the other polymorphisms, all 3 genotypes were identified. Details on polymorphisms and their genotype frequencies are presented in Table 1.

Daughter yield deviations (DYD) of bulls, calculated following Liu et al. (2004) from a routine national genetic evaluation with a random regression test day model, were used as phenotypic measures of the milk, fat, and protein yield merits of a bull at first and second lactations. Simple descriptive statistics of the phenotypic traits are presented in Table 2 . Note that following Liu et al. (2004), DYD were scaled by 2 to be on the same basis as EBV.

\section{Polymorphism Assessment}

Deoxyribonucleic acid for molecular analyses was extracted from peripheral blood using the standard phe- 
Table 1. Description of the single nucleotide polymorphisms considered in this study

\begin{tabular}{|c|c|c|c|c|c|}
\hline$\frac{\text { Code }}{\text { T945M }}$ & $\begin{array}{r}\text { Gene } \\
\text { Leptin receptor (LEPR) }\end{array}$ & $\begin{array}{l}\text { Location } \\
\text { BTA03 }\end{array}$ & \multicolumn{3}{|c|}{ Genotypes and genotype frequencies } \\
\hline $\begin{array}{l}\text { Y7F } \\
\text { R25C } \\
\text { A80V } \\
\text { C(-963)T }\end{array}$ & Leptin gene (LEP) & BTA04 & $\begin{array}{l}\mathrm{AA}=0.98 \\
\mathrm{TT}=0.16 \\
\mathrm{CC}=0.47 \\
\mathrm{CC}=0.28\end{array}$ & $\begin{array}{l}\mathrm{AT}=0.02 \\
\mathrm{CT}=0.57 \\
\mathrm{CT}=0.45 \\
\mathrm{CT}=0.57\end{array}$ & $\begin{array}{l}\mathrm{CC}=0.27 \\
\mathrm{TT}=0.08 \\
\mathrm{TT}=0.15\end{array}$ \\
\hline $\mathrm{K} 232 \mathrm{~A}$ & Diacylglycerol acyltransferase 1 gene (DGAT1) & BTA14 & $\mathrm{AA} / \mathrm{AA}=0.456$ & $\mathrm{AA} / \mathrm{GC}=0.267$ & $\mathrm{GC} / \mathrm{GC}=0.277$ \\
\hline
\end{tabular}

nol method. Genotypes were determined using PCRRFLP. Primers for the PCR (Table 3) were established from gene sequences available in the GenBank database (accession numbers: BTN1A1-Z93323, DGAT1AY065621, LEP-U50365, LEPR-AJ580801) with the use of Primer3 software (http://frodo.wi.mit.edu/ cgi-bin/primer3/primer3.cgi).

The PCR reaction mixture contained a total of 20 to $50 \mathrm{ng}$ of genomic DNA, 0.5 units of Taq polymerase (Fermentas, Vilnius, Lithuania), $1 \times$ PCR buffer with $\left(\mathrm{NH}_{4}\right)_{2} \mathrm{SO}_{4}, 2 \mathrm{mM} \mathrm{MgCl} 2,5 \%$ dimethyl sulfoxide, $1 \mu M$ each primer (Institute of Biochemistry and Biophysics, Polish Academy of Sciences, Warsaw), and $200 \mu M$ each dNTP (Fermentas). Thermal cycling conditions included an initial denaturation at $94^{\circ} \mathrm{C}$ for $5 \mathrm{~min}$, followed by 30 cycles of $94^{\circ} \mathrm{C}$ for $30 \mathrm{~s}$, annealing temperature (Table 3) for $30 \mathrm{~s}$, and $72^{\circ} \mathrm{C}$ for $40 \mathrm{~s}$, followed by the final extension at $72^{\circ} \mathrm{C}$ for $5 \mathrm{~min}$. Amplified fragments were digested overnight with 5 units of respective restriction endonucleases (Fermentas) and were then subjected to electrophoretic separation in 2.5\% ethidium bromide stained agarose gel (Basica GQT, Prona, Spain).

\section{Statistical Modeling}

Models. A series of mixed models were applied to the data with the general structure given by:

$$
\mathbf{y}=\mathbf{X}_{\beta} \boldsymbol{\beta}+\mathbf{X}_{q} \mathbf{q}+\mathbf{Z} \boldsymbol{\alpha}+\mathbf{e},
$$

where $\mathbf{y}=$ a vector of trait measures (DYD) transformed to the standard normal distribution; $\boldsymbol{\beta}=$ a vector of fixed nongenetic effects comprising a general mean and the birth year of a bull; $\mathbf{q}=$ a vector of fixed SNP effects; $\alpha=$ a vector of random polygenic effects assuming $\alpha$ $N\left(0, \mathbf{A} \sigma_{a}^{2}\right)$, where $\mathbf{A}=$ additive relationships among individuals and $\sigma_{a}^{2}=$ a component of the total additive genetic variance attributed to polygenes; $\mathbf{e}=$ a vector of random errors assuming $\mathbf{e} \sim N\left(0, \mathbf{R} \sigma_{e}^{2}\right)$, where $\mathbf{R}=\mathrm{a}$ diagonal matrix with the reciprocal of the number of effective daughters calculated following Liu et al. (2004) and $\sigma_{e}^{2}=$ the error variance; and $\mathbf{X}_{\beta} \mathbf{X}_{q}$, and $\mathbf{Z}=$ corresponding design matrices. Both variance components were assumed as known (i.e., were not estimated) with $\sigma_{a}^{2}=0.3$ and $\sigma_{e}^{2}=0.6$. Differences between applied models comprised $\mathbf{q}$. The $i$ th SNP in $\mathbf{q}$ was modeled through its additive $\left(a_{i}\right)$ and dominance $\left(d_{i}\right)$ effects, whereas in multiple-SNP models, additional pairwise epistatic effects between $i$ th and $j$ th SNP were considered, comprising an additive-by-additive epistasis $\left(\delta_{i j}^{a a}\right)$, additiveby-dominance epistasis $\left(\delta_{i j}^{a d}\right)$, dominance-by-additive epistasis $\left(\delta_{i j}^{d a}\right)$, and dominance-by-dominance epistasis $\left(\delta_{i j}^{d d}\right)$. Corresponding elements of $\mathbf{X}_{q}$ were set up following the $\mathrm{F}_{\infty}$ metric model defined by Kao and Zeng (2002), where codes for effects are given as follows:

Table 2. Estimated means and standard deviations of phenotypic trait measures

\begin{tabular}{|c|c|c|c|c|}
\hline \multirow[b]{2}{*}{ Trait } & \multicolumn{2}{|c|}{$\mathrm{DYD}^{1}$} & \multicolumn{2}{|c|}{ EBV } \\
\hline & Mean & SD & Mean & $\mathrm{SD}$ \\
\hline Milk yield, first parity & $298.5 \mathrm{~kg}$ & $323.9 \mathrm{~kg}$ & $299.7 \mathrm{~kg}$ & $308.8 \mathrm{~kg}$ \\
\hline Milk yield, second parity & $353.3 \mathrm{~kg}$ & $395.2 \mathrm{~kg}$ & $355.3 \mathrm{~kg}$ & $371.0 \mathrm{~kg}$ \\
\hline Protein yield, first parity & $8.3 \mathrm{~kg}$ & $8.5 \mathrm{~kg}$ & $8.3 \mathrm{~kg}$ & $8.0 \mathrm{~kg}$ \\
\hline Protein yield, second parity & $8.8 \mathrm{~kg}$ & $11.8 \mathrm{~kg}$ & $8.9 \mathrm{~kg}$ & $10.9 \mathrm{~kg}$ \\
\hline Fat yield, first parity & $8.4 \mathrm{~kg}$ & $13.0 \mathrm{~kg}$ & $8.3 \mathrm{~kg}$ & $12.2 \mathrm{~kg}$ \\
\hline Fat yield, second parity & $9.5 \mathrm{~kg}$ & $17.3 \mathrm{~kg}$ & $9.4 \mathrm{~kg}$ & $16.1 \mathrm{~kg}$ \\
\hline
\end{tabular}

${ }^{1} \mathrm{DYD}=$ daughter yield deviations. 
Table 3. Selected PCR-RFLP conditions for the analyzed polymorphisms

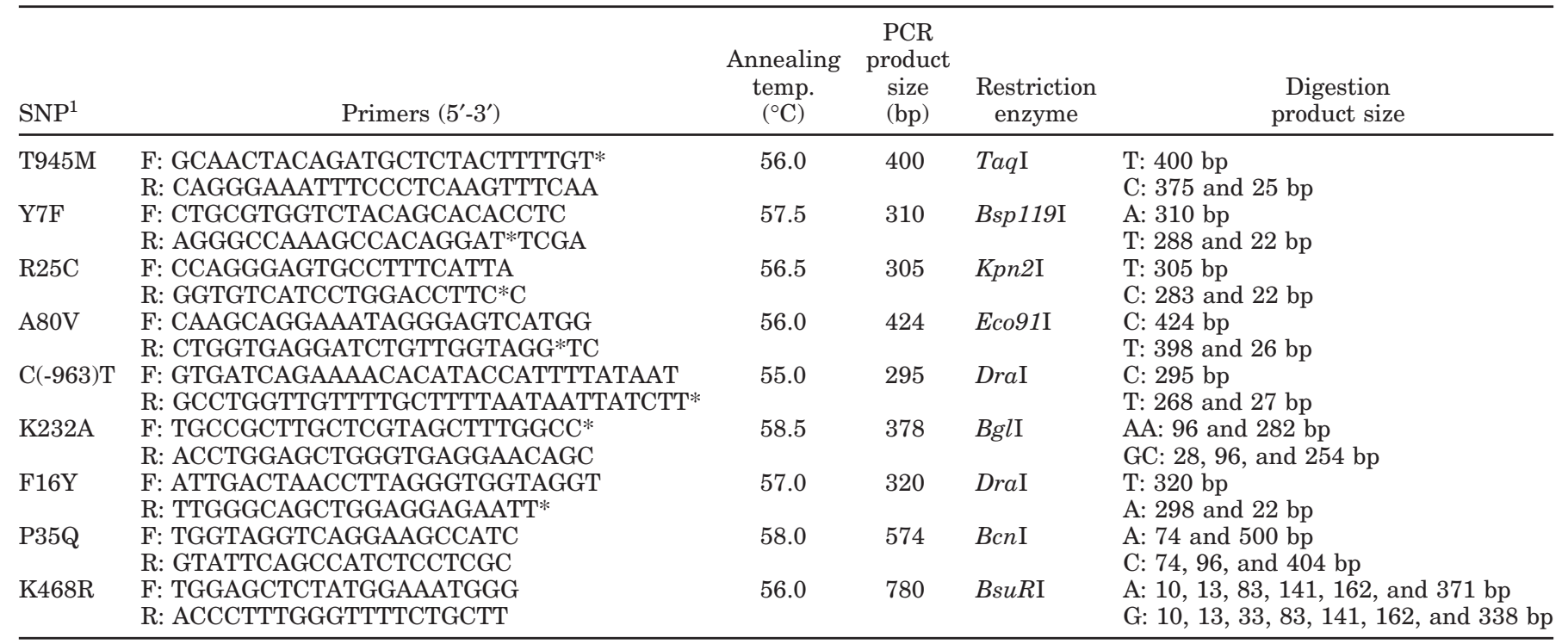

${ }^{1} \mathrm{SNP}=$ single nucleotide polymorphisms.

*An intentional mismatch incorporating the restriction site to a sequence.

$$
\begin{gathered}
x_{a i}=\left\{\begin{array}{l}
1 \text { for a homozygous SNP (say QQ) } \\
0 \text { for a heterozygous SNP (say Qq) } \\
-1 \text { for a homozygous SNP (say qq) }
\end{array}\right. \\
\text { for an additive effect, } \\
x_{d i}=\left\{\begin{array}{l}
0 \text { for } \mathrm{QQ} \text { and qq } \\
1 \text { for } \mathrm{Qq}
\end{array}\right. \text { for a dominance effect, }
\end{gathered}
$$

and $x_{\delta i j}^{a a}=x_{a i} x_{a j}, x_{\delta i j}^{a d}=x_{a i} x_{d j}, x_{\delta i j}^{d a}=x_{d i} x_{a j}$, and $x_{\delta i j}^{d d}=x_{d i} x_{d j}$, respectively, for the 4 types of epistatic effects.

In the analysis, 57 models with the following parameterization of $\mathbf{q}$ were considered:

a) No SNP model $-\mathbf{y}=\mathbf{X}_{\beta} \boldsymbol{\beta}+\mathbf{Z} \boldsymbol{\alpha}+\mathbf{e}$.

b) Nine single SNP models with an additive SNP effect $-\mathrm{q}=\mathrm{a}_{i}$ for $i$ th SNP.

c) Forty-seven models, which additionally contained genetically irrelevant effects of dominance and epistasis confounded with additive effects, including:

- Nine single SNP models with additive and dominance SNP effects:

$$
\mathbf{q}^{T}=\left[\begin{array}{ll}
a_{i} & d_{i}
\end{array}\right] \text { for } i \text { th SNP; }
$$

- A model with additive and dominance effects of all SNP:

$$
\mathbf{q}^{T}=\left[\begin{array}{cc}
\sum_{i=1}^{9}\left(a_{i}\right. & \left.d_{i}\right)
\end{array}\right]
$$

- Thirty-five models with all SNP and a single pairwise additive-by-additive epistasis:

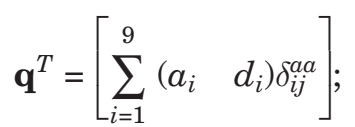

- A model with all SNP and all possible pairwise additive-by-additive epistatic effects:

$$
\mathbf{q}^{T}=\left[\sum_{i=1}^{9}\left(a_{i} \quad d_{i}\right) \sum_{i=1}^{9} \sum_{j=i+1}^{9} \delta_{i j}^{a a}\right] ;
$$

- A full model with all SNPs and all possible pairwise epistatic effects:

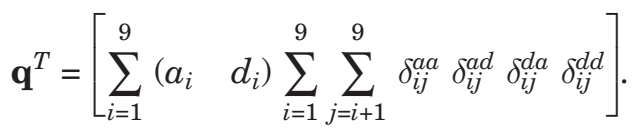

Model Selection. The following criteria were considered for model selection:

a) The standard BIC (Schwarz, 1978):

$$
\mathrm{BIC}=\ln L-\frac{1}{2} k \ln n,
$$

where $L=$ model likelihood; $k=$ the number of fitted parameters; and $n=$ the number of observations.

b) A modified version of BIC ( $\mathbf{m B I C}$ ) developed by Baierl et al. (2006) for the purpose of a genome scan (i.e., multiple linked markers), enabling dif- 


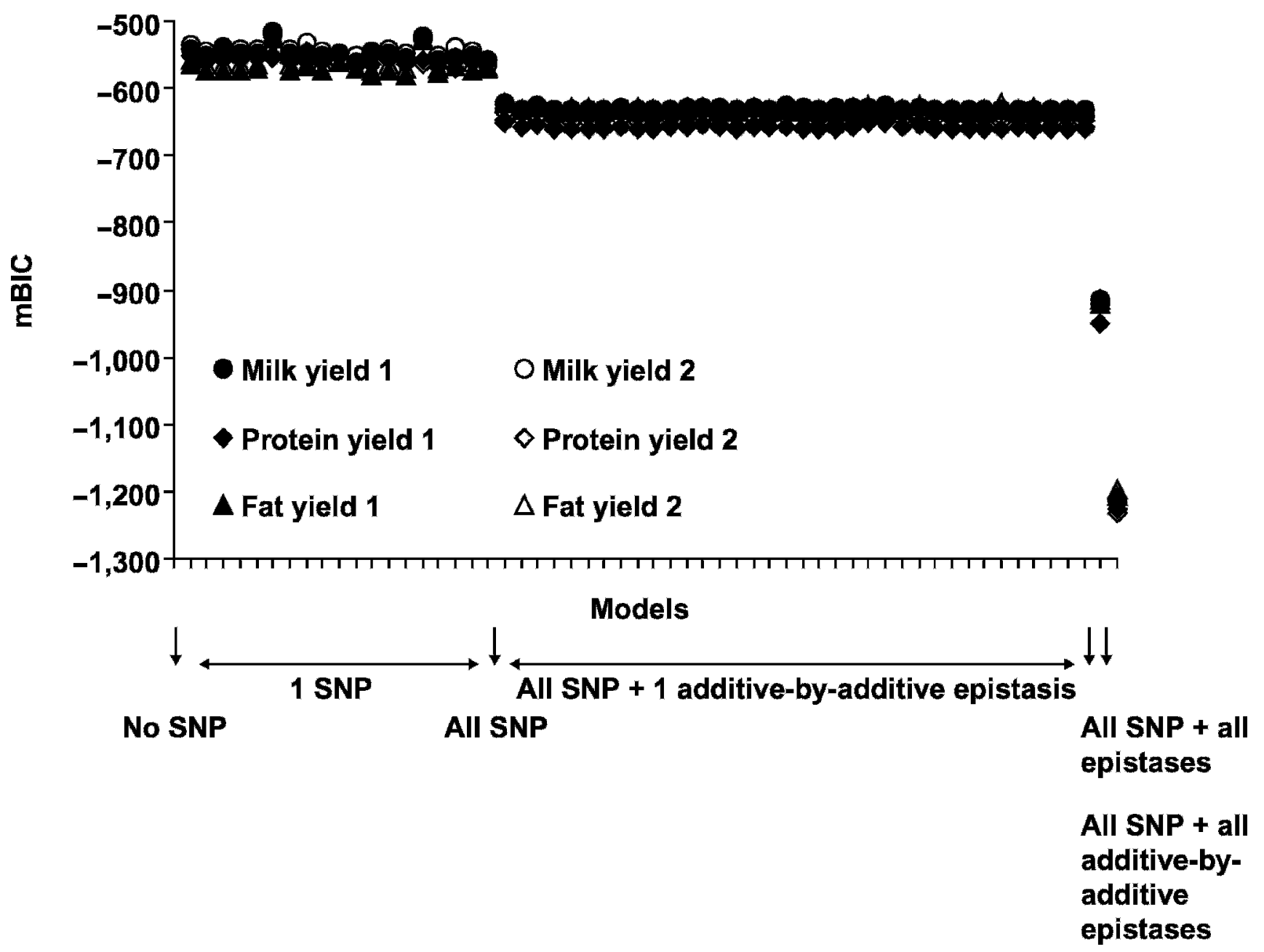

Figure 1. Modified Bayesian information criterion (mBIC) for different models and traits.

ferentiation between marginal (additive and dominance) marker effects and interaction (epistatic) effects between markers:

$$
\begin{aligned}
\mathrm{mBIC}= & \ln L-(p+q) \ln n-2 p \ln \left(\frac{m}{1.1}-1\right) \\
& -2 q \ln \left(\frac{m(m-1)}{1.1}-1\right),
\end{aligned}
$$

where $p$ and $q$ = the numbers of fitted main and epistatic effects, respectively, and $m=$ the number of markers.

\section{RESULTS}

Figure 1 shows mBIC for all the traits and models considered. Keeping in mind that high values of mBIC indicate preferred models, it is evident that, regardless of a trait, the criterion selected parsimonious models, whereas highly parameterized models received very high penalty. In detail, for milk and fat yields at both parities, a model with the highest mBIC was the one containing only the additive effect of K232A. The additive genetic effect of K232A expressed as half of the difference between $\mathrm{AA} / \mathrm{AA}$ and $\mathrm{GC} / \mathrm{GC}$ genotypes amounted to $-107.4 \mathrm{~kg}$ of milk at first parity and -120 $\mathrm{kg}$ of milk at second parity. Thus, it is the GC allele that resulted in the increase of milk yield. For fat yield, the additive effects were 5.4 and $6.8 \mathrm{~kg}$ of fat for first and second parity, respectively, with the AA allele provoking an increase of fat production in milk. For protein yield, selected models differed between parities so that for the first parity, again, the additive effect of K232A amounting to $-1.6 \mathrm{~kg}$ of protein (increasing allele GC) and for the second parity, the additive effect of A80V within the leptin gene estimated to $0.4 \mathrm{~kg}$ of protein (increasing allele is $\mathrm{C}$ over $\mathrm{T}$ ) were assigned the highest mBIC. Note that based on mBIC, neither dominant nor epistatic effects improved the fitting of the model. 
As expected from the lower penalty term, compared with $\mathrm{mBIC}$, the original BIC usually selected models with higher parameterization also including the dominance and additive effects, which were genetically irrelevant for the analyzed trait. More precisely, the selected models were:

a) for milk yields at first parity, the model with the additive effect of K232A (same for mBIC and BIC);

b) for milk yield at second parity, the model with additive and dominance effects of K232A;

c) for protein yield at first parity, the model defined by

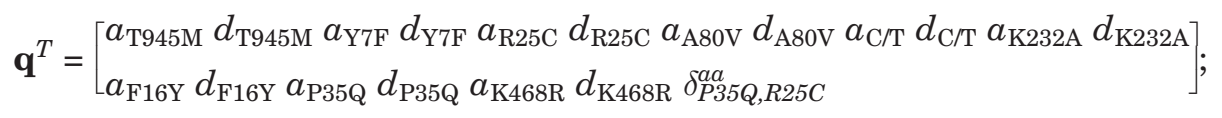

d) for protein yield at second parity, the model with the additive effect of A80V (same for mBIC and BIC);

e) for fat yield at first parity, the model defined by

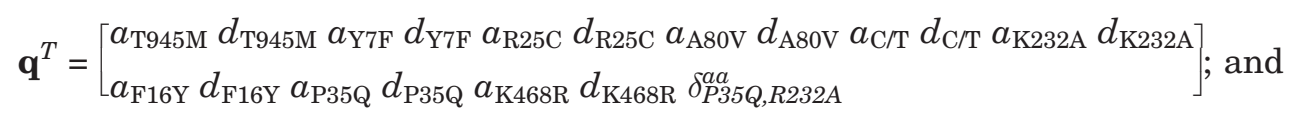

f) for fat yield at second parity, the model defined by

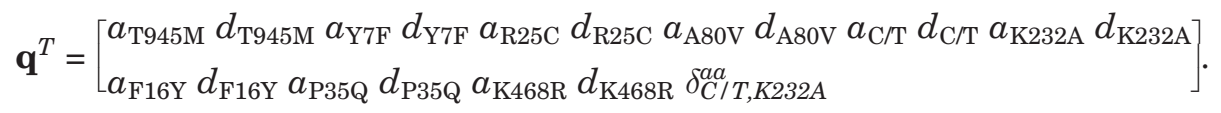

A general overview of the estimated SNP effects, visualized for an example of milk yield at first lactation, is shown in Figures 2 to 4 . Both additive effects and their precision (expressed by standard errors) did not differ much among all the 3 models without epistasis. Incorporation of epistasis resulted in markedly different estimates and highly elevated standard errors. Figure 2 summarizes solutions for additive effects of the SNP under 5 different models. These were as follows: a model with an additive effect of a single SNP, a model with additive and dominance effects of a single SNP, a model with additive and dominance effects of all SNP, a model with additive and dominance effects of all SNP and all possible pairwise additive-by-additive epistases, and a model with additive and dominance effects of all SNP and all possible pairwise epistases. A similar pattern

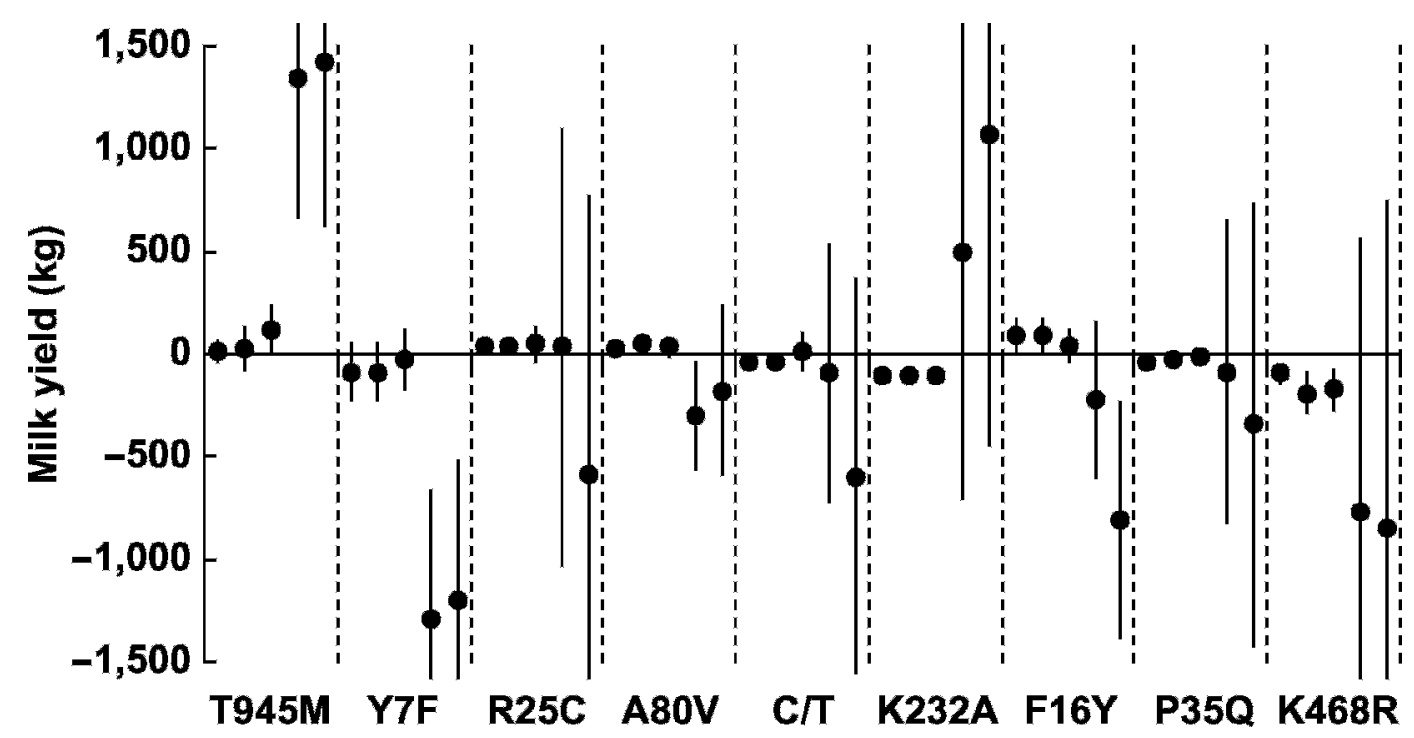

Figure 2. Estimates of additive effects of each single nucleotide polymorphism (SNP) on milk yield at first lactation with corresponding 95\% normal confidence intervals. For each SNP, from left to right, estimates from the following: a model with an additive effect of a single SNP, a model with additive and dominance effects of a single SNP, a model with additive and dominance effects of all SNP, a model with additive and dominance effects of all SNP and all possible pairwise additive-by-additive epistases, and a model with additive and dominance effects of all SNP and all possible pairwise epistases are given. 


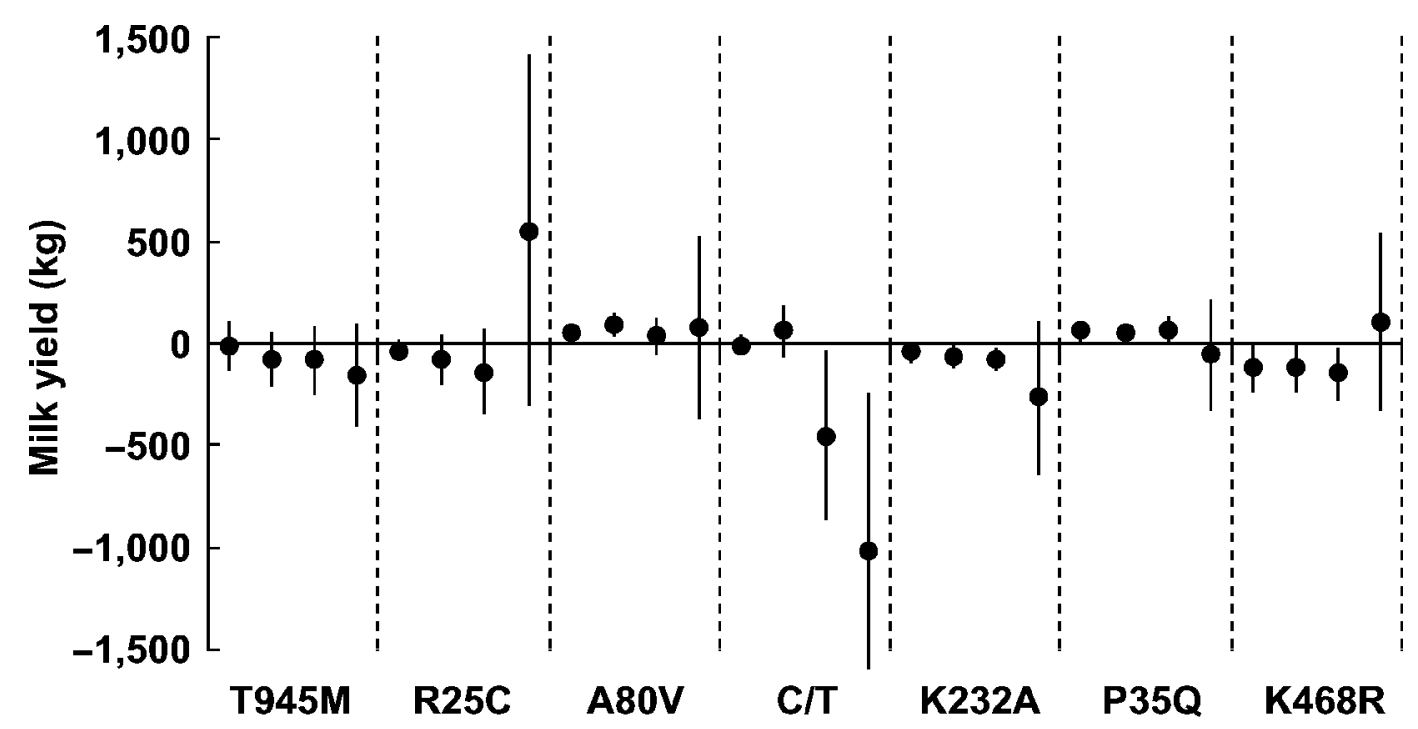

Figure 3. Estimates of dominance effects of each single nucleotide polymorphism (SNP) on milk yield at first lactation with corresponding 95\% normal confidence intervals. For each SNP, from left to right, estimates from the following: a model with additive and dominance effects of a single SNP, a model with additive and dominance effects of all SNP, a model with additive and dominance effects of all SNP and all possible pairwise additive-by-additive epistases, and a model with additive and dominance effects of all SNP and all possible pairwise epistases are given.

was observed regarding the dominance effects; when the epistasis components involving a dominance effect were not included in the model, estimated dominance showed similar values and precision across models (Figure 3). Also, note that the majority of confidence intervals for dominance effects contained zero-equivalent to no dominance. Figure 4 presents solutions for additive-by-additive interactions, estimated under a model with pairwise additive-by-additive epistasis only and a model with all possible pairwise epistases. Depending on the model used, estimated epistasis effects differed by $-479 \mathrm{~kg}$ of milk on average over all estimable effects, indicating that the model with additive-by-additive epistasis usually only resulted in higher estimates. As compared between the 2 abovementioned models, the smallest difference amounted to only $8 \mathrm{~kg}$ of milk for epistasis between $\mathrm{Y} 7 \mathrm{~F}$ and $\mathrm{R} 25 \mathrm{C}$ within the leptin gene and between K468R within the BTN1A1 and A80V within the leptin

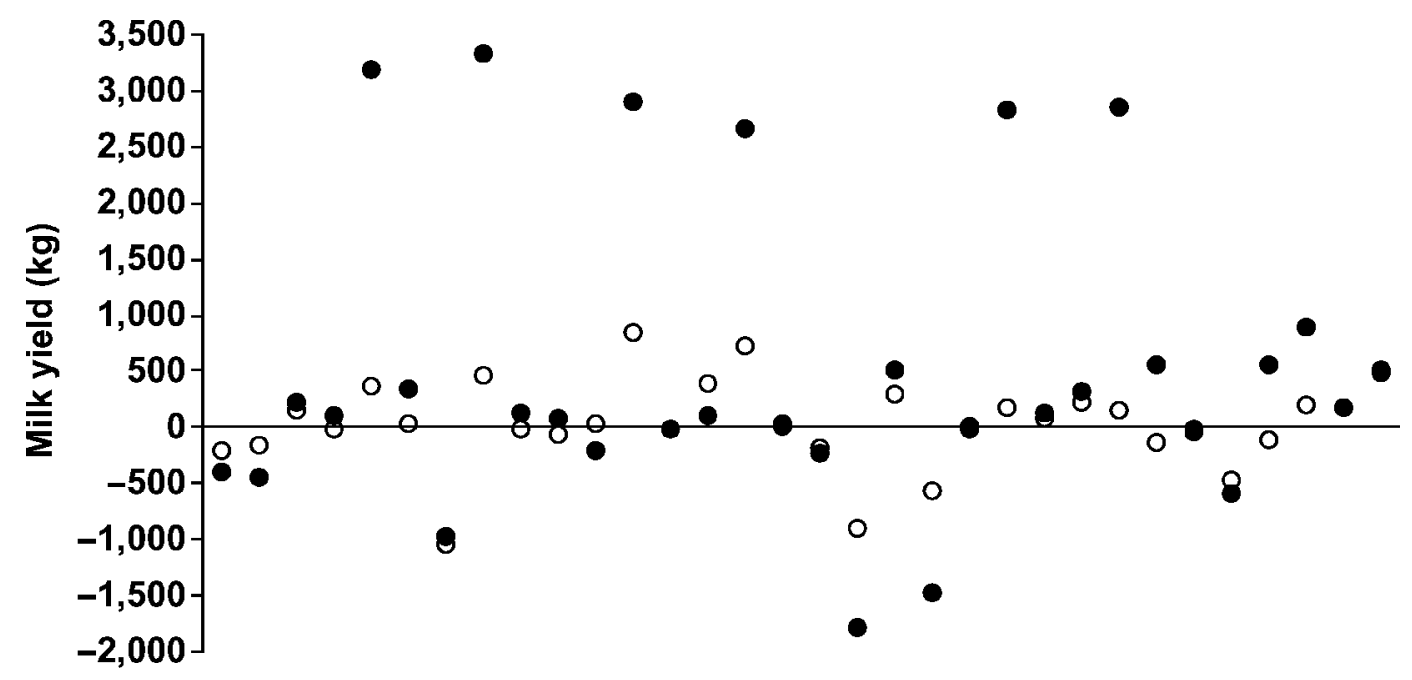

Figure 4. Point estimates of additive-by-additive effects of each single nucleotide polymorphism (SNP) on milk yield at first lactation based on a model with additive and dominance effects of all SNP and all possible pairwise additive-by-additive epistases $(O)$ and a model with additive and dominance effects of all SNP and all possible pairwise epistases (-). 
gene, whereas the largest estimated discrepancy was as high as $-2,859 \mathrm{~kg}$ of milk for T945M within the leptin receptor and $\mathrm{C} / \mathrm{T}$ substitution within the leptin gene.

\section{DISCUSSION}

Presented results show that from all the polymorphisms considered, DGAT1 had a much larger additive effect on milk and fat yields as well as on protein yield at first parity than the other SNP considered. A pronounced effect of DGAT1 K232A mutation on dairy traits has been reported in all cattle populations examined so far, including the Jersey, Fleckvieh, and Angeln breeds, as well as German, Dutch, and New Zealand HolsteinFriesians. Several studies have shown the positive effect of the Lys-encoding AA allele on fat yield, its negative influence on milk yield, and a much lower decreasing effect on protein yield. Consequently, the AA variant has been shown to be strongly associated with increased fat content and less markedly with an increased protein percentage (Grisart et al., 2002; Thaller et al., 2003; Bennewitz et al., 2004; Sanders et al., 2006). Although K232A affected individual milk traits in the same direction, the estimated allele substitution effects differed between cattle populations. The lowest Lys variant effects $(-87.69,3.21$, and $-1.31 \mathrm{~kg}$ for milk, fat, and protein yields, respectively) have been reported for German Angeln cattle (Sanders et al., 2006). In Holstein-Friesians, the effect of K232A on milk yield traits seems to be a little higher. The Lys-encoding allele effects estimated by Spelman et al. (2002) amounted to $-134 \mathrm{~kg}$ for milk yield, $5.74 \mathrm{~kg}$ for fat yield, and $-2.45 \mathrm{~kg}$ for protein yield. Similar values were obtained by Grisart et al. (2002), Thaller et al. (2003), and in the current study. The mode of DGAT1 inheritance seems to be almost completely additive (Grisart et al., 2002; Sanders et al., 2006), although Thaller et al. (2003) did not exclude a partly recessive inheritance of the Lys-encoding variant.

The fact that neither dominance nor epistasis was present in the analyzed data was expected and originates from using as a dependent variable additive genetic values of bulls expressed by DYD and not the original trait measurements. Still, the idea behind consideration of many theoretically possible inheritance models was to compare estimates of the same effect under different models. By using a real data set, it was illustrated that the parameter estimates differed among models with different parameterization. This problem was addressed by Zeng et al. (2005) and illustrated by simulation results. Recently, P. Biecek and W. Klonecki (Institute of Mathematics and Informatics, Wrocław Technical University, Poland; personal communication) presented a mathematical description of the differences between parameter estimates under different genetic models and levels of disequilibrium. Precisely, following Zeng et al. (2005), assuming the frequency of both alleles as 0.5 and no linkage disequilibrium, in models without epistasis, the additive effect was defined as half of the difference between both homozygote genotypic values: $\mathrm{a}=$ $\frac{G_{Q Q}-G_{q q}}{2}$, and the dominance effect was defined as the difference between the heterozygote genotypic value and the mean of both homozygous genotypic values: $\mathrm{d}=G_{Q q}$ $-\frac{G_{Q Q}-G_{q q}}{2}$, regardless of the number of main SNP effects fitted in the model. Figures 2 and 3, showing no marked differences between $\hat{a}$ and $\hat{d}$ among no epistasis models, illustrate that it is still the case under real data conditions-with allele frequencies different than $50 \%$, nonzero linkage disequilibrium varying between different pairs of loci, finite sample size, and missing observations. Additionally, Zeng et al. (2005) showed that when pairwise epistases were included in the model, the estimates of marginal effects of one locus became a function of genotypic values at other loci and thus resulted in different estimates. This is again illustrated by Figures 2 and 3.

Comparing both model selection criteria applied (i.e., $\mathrm{mBIC}$ and BIC), it is evident that BIC selected much more highly parameterized models. This observation is consistent with the theoretical explanation given by Bogdan et al. (2004). While analyzing real data, it was shown that in practice the likelihood penalty incorporated into the mBIC criterion by Baierl et al. (2006) not only resulted in the selection of models with low parameterization but also properly excluded models with dominance and epistasis, which should not be observed when DYD was used as a dependent variable.

By definition, DYD represents half of the additive genetic value of a bull, whereas EBV is composed of the additive genetic values of the parents of a bull and progeny information. When the EBV of a bull is estimated based on a large number of progeny, the relative effect of the parental component is diminished, and thus DYD and EBV become similar, as is shown by Table 2. Still, Table 2 also indicates DYD have a slightly higher variance than EBV. It is consistent with the fact that in contrast to EBV, DYD contain the residual component out of the genetic evaluation model. Consequently, a variance of $\mathrm{EBV}$ is equivalent to the additive polygenic variance times reliability of the $\mathrm{EBV}$, whereas a variance of DYD additionally contains a residual component.

\section{CONCLUSIONS}

Estimated effects of candidate polymorphisms are the ideal input information for marker-assisted selection (Schaeffer, 2006). However, when considering the lack 
of consistency of those estimates depending on the model used, they should be treated with caution. In the era of a wide accessibility of thousands of SNP genotypes per animal through SNP chips, it is thus important to report estimates out of an optimally fitted model. To be able to identify such a model among many theoretically possible models, the appropriate model selection criteria must be applied. They should not only be easy to calculate, but also it is very important that they hold the assumed type I error level.

\section{ACKNOWLEDGMENTS}

The study was partly financed by the Polish State Committee for Scientific Research, grant number 2 P06D 01726.

\section{REFERENCES}

Baierl, A., M. Bogdan, F. Frommlet, and A. Futschik. 2006. On locating multiple interacting quantitative trait loci in intercross designs. Genetics 173:1693-1703.

Bennewitz, J., N. Reinsch, S. Paul, C. Looft, B. Kaupe, C. Weimann, G. Erhardt, G. Thaller, C. Kühn, M. Schwerin, H. Thomsen, F. Reinhardt, R. Reents, and E. Kalm. 2004. The DGAT1 K232A mutation is not solely responsible for the milk production quantitative trait locus on the bovine chromosome 14. J. Dairy Sci. 87:431-442.

Bogdan, M., J. K. Gosh, and R. Doerge. 2004. Modifying the Schwarz Bayesian information criterion to locate multiple interacting quantitative trait loci. Genetics 167:989-999.

Buchanan, F. C., A. G. van Kessel, C. Waldner, D. A. Christensen, B. Laarveld, and S. M. Schmutz. 2003. An association between a leptin single nucleotide polymorphism and milk and protein yield. J. Dairy Sci. 86:3164-3166.

Coppieters, W., J. Riquet, J.-J. Arranz, P. Berzi, N. Cambisano, B. Grisart, L. Karim, F. Marcq, L. Moreau, C. Nezer, P. Simon, P. Vanmanshoven, D. Wagenaar, and M. Georges. 1998. A QTL with major effect on milk yield and composition maps to bovine chromosome 14. Mamm. Genome 9:540-544.

Feuermann, Y., S. J. Mabjeesh, and A. Shamay. 2004. Leptin affects prolactin action on milk protein and fat synthesis in the bovine mammary gland. J. Dairy Sci. 87:2941-2946.

Fruhbeck, G. 2001. A heliocentric view of leptin. Proc. Nutr. Soc. 60:301-318.

Grisart, B., W. Coppieters, F. Farnir, L. Karim, C. Ford, P. Berzi, N. Cambisano, M. Mni, S. Reid, P. Simon, R. Spelman, M. Georges, and R. Snell. 2002. Positional candidate cloning of a QTL in dairy cattle: Identification of a missense mutation in the bovine DGAT1 gene with major effect on milk yield and composition. Genome Res. 12:222-231.

Grisart, B., F. Farnir, L. Karim, N. Cambisano, J.-J. Kim, A. Kvasz, M. Mni, P. Simon, J.-M. Frère, W. Coppieters, and M. Georges. 2004. Genetic and functional confirmation of the causality of the DGAT1 K232A quantitative trait nucleotide in affecting milk yield and composition. Proc. Natl. Acad. Sci. USA 101:2398-2403.

Houseknecht, K. L., C. A. Baile, R. L. Matteri, and M. E. Spurlock. 1998. The biology of leptin: A review. J. Anim. Sci. 76:1405-1420.

Husaini, Y., R. J. Wilkins, and H. W. Davey. 1999. Identification of five point mutations, including an AluI RFLP, in the bovine butyrophilin gene. Anim. Genet. 30:400-401.

Kao, C. H., and Z.-B. Zeng. 2002. Modeling epistasis of quantitative trait loci using Cockerham's model. Genetics 160:1243-1261.
Komisarek, J., J. Szyda, A. Michalak, and Z. Dorynek. 2005. Impact of leptin gene polymorphisms on breeding value for milk production traits in cattle. J. Anim. Feed Sci. 14:491-500.

Konfortov, B. A., V. E. Licence, and J. R. Miller. 1999. Re-sequencing of DNA from a diverse panel of cattle reveals a high level of polymorphism in both intron and exon. Mamm. Genome 10:1142-1145.

Lagonigro, R., P. Wiener, F. Pilla, J. A. Woolliams, and J. L. Williams. 2003. A new mutation in the coding region of the bovine leptin gene associated with feed intake. Anim. Genet. 34:371-374.

Liefers, S. C., R. F. Veerkamp, M. F. W. te Pas, C. Delavaud, Y. Chilliard, M. Platje, and T. van der Lende. 2005. Leptin promoter mutation affects leptin levels and performance traits in dairy cows. Anim. Genet. 36:111-118.

Liefers, S. C., R. F. Veerkamp, M. F. te Pas, C. Delavaud, Y. Chilliard, and T. van der Lende. 2004. A missense mutation in the bovine leptin receptor gene is associated with leptin concentrations during late pregnancy. Anim. Genet. 35:138-141.

Liu, Z., F. Reinhardt, A. Bunger, and R. Reents. 2004. Derivation and calculation of approximate reliabilities and daughter yielddeviations of a random regression test-day model for genetic evaluation of dairy cattle. J. Dairy Sci. 87:1896-1907.

Mather, I. H. 2000. A review and proposed nomenclature for major proteins of the milk-fat globule membrane. J. Dairy Sci. 83:203247.

Ogg, S. L., A. K. Weldon, L. Dobbie, A. J. H. Smith, and I. H. Mather. 2004. Expression of butyrophilin (BTN1A1) in lactating mammary gland is essential for the regulated secretion of milk-lipid droplets. Proc. Natl. Acad. Sci. USA 101:10084-10089.

Riquet, J., W. Coppieters, N. Cambisano, J.-J. Arranz, P. Berzi, S. Davis, B. Grisart, F. Farnir, L. Karim, M. Mni, P. Simon, J. F. Taylor, P. Vanmanshoven, D. Wagenaar, J. E. Womack, and M. Georges. 1999. Identity-by-decent fine-mapping of QTL in outbred populations: Application to milk production in dairy cattle. Proc. Natl. Acad. Sci. USA 96:9252-9257.

Sanders, K., J. Bennewitz, N. Reinsch, G. Thaller, E.-M. Prinzenberg, C. Kühn, and E. Kalm. 2006. Characterization of the DGAT1 mutations and the CSN1S1 promoter in the German Angeln dairy cattle population. J. Dairy Sci. 89:3164-3174.

Schaeffer, L. R. 2006. Strategy for applying genome-wide selection in dairy cattle. J. Anim. Breed. Genet. 123:218-223.

Schwarz, G. 1978. Estimating the dimension of a model. Ann. Stat. 6:461-464.

Seyfert, H.-M., and F. Lüthen. 1998. The structure of the bovine butyrophilin encoding gene differs grossly from mouse concerning promoter localization and exon organization of the S-untranslated region. Proc. 6th World Congr. Genet. Appl. Livest. Prod. 25:51-54.

Silva, L. F. P., M. J. Vandehaar, M. S. Weber Nielsen, and G. W. Smith. 2002. Evidence for a local effect of leptin in bovine mammary gland. J. Dairy Sci. 85:3277-3286.

Smith, S. J., S. Cases, D. R. Jensen, H. C. Chen, E. Sande, B. Tow, D. A. Sanan, J. Raber, R. H. Eckel, and R. V. Farese Jr. 2000. Obesity resistance and multiple mechanisms of triglyceride synthesis in mice lacking Dgat. Nat. Genet. 25:87-90.

Spelman, R. J., C. A. Ford, P. Mcelhinney, G. C. Gregory, and R. G. Snell. 2002. Characterization of the DGAT1 gene in the New Zealand dairy population. J. Dairy Sci. 85:3514-3517.

Taylor, C., M. Everest, and C. Smith. 1996. Restriction fragment length polymorphism in amplification products of the bovine butyrophilin gene: Assignment of bovine butyrophilin to bovine chromosome 23. Anim. Genet. 27:183-185.

Thaller, G., W. Krämer, A. Winter, B. Kaupe, G. Erhardt, and R. Fries. 2003. Effects of DGAT1 variants on milk production traits in German cattle breeds. J. Anim. Sci. 81:1911-1918.

Winter, A., W. Krämer, F. A. O. Werner, S. Kollers, S. Kata, G. Durstewitz, J. Buitkamp, J. E. Womack, G. Thaller, and R. Fries. 2002. Association of a lysine-232/alanine polymorphism in a bovine gene encoding acyl-CoA:diacylglycerol acyltransferase (DGAT1) with variation at a quantitative trait locus for milk fat content. Proc. Natl. Acad. Sci. USA 99:9300-9305.

Zeng, Z.-B., T. Wang, and W. Zou. 2005. Modeling quantitative trait loci and interpretation of models. Genetics 169:1711-1725. 